\section{HIV-associated tuberculosis}

International Journal of STD \& AIDS 202I, Vol. 0(0) I-II (C) The Author(s) 202 (c) (1) (8)

Article reuse guidelines: sagepub.com/journals-permissions DOI: $10.1177 / 0956462421992257$ journals.sagepub.com/home/std

\author{
Yohhei Hamada, MD, MPH ${ }^{1,2, *} \odot$, Haileyesus Getahun, MD, \\ $\mathrm{PhD}, \mathrm{MPH}^{3, *}$, Birkneh Tilahun Tadesse, $\mathrm{MD}, \mathrm{PhD}^{4}$, and \\ Nathan Ford, PhD, FRCPE
}

\begin{abstract}
Tuberculosis (TB) remains a leading cause of morbidity and mortality among people living with HIV. HIV-associated TB disproportionally affects African countries, particularly vulnerable groups at risk for both TB and HIV. Currently available TB diagnostics perform poorly in people living with HIV; however, new diagnostics such as Xpert Ultra and lateral flow urine lipoarabinomannan assays can greatly facilitate diagnosis of TB in people living with HIV. TB preventive treatment has been underutilized despite its proven benefits independent of antiretroviral therapy (ART). Shorter regimens using rifapentine can support increased availability and scale-up. Mortality is high in people with HIV-associated TB, and timely initiation of ART is critical. Programs should provide decentralized and integrated TB and HIV care in settings with high burden of both diseases to improve access to services that diagnose TB and HIV as early as possible. The new prevention and diagnosis tools recently recommended by WHO offer an immense opportunity to advance our fight against HIVassociated TB. They should be made widely available and scaled up rapidly supported by adequate funding with robust monitoring of the uptake to advance global TB elimination.
\end{abstract}

\title{
Keywords
}

AIDS, preventive treatment, drug-resistant tuberculosis, antiretroviral treatment

Date received: 6 October 2020; accepted: 23 November 2020

\section{Introduction}

With the rapid upsurge of the global HIV epidemic in the late 1980s, TB incidence rose in HIV-prevalent countries despite successful implementation of the Directly Observed Treatment Short-course (DOTS). This eventually led to criticism about the failure of the DOTS strategy in addressing HIVassociated TB. ${ }^{1}$ Since then, collaborative TB and HIV activities have been established and scaled up. ${ }^{2}$ Due to its implementation, deaths from HIV-associated TB declined globally by $60 \%$ between 2000 and $2018 .{ }^{3}$ Nonetheless, TB remains the leading cause of deaths in people living with HIV. In this review, we summarize HIV-associated TB epidemiology, pathogenesis, clinical presentation and care, the current global programmatic response, and key challenges.

\section{Epidemiology of HIV-associated TB}

TB is the leading cause of HIV-associated hospitalization and death among adults and children living with HIV worldwide, ${ }^{4}$ and accounted for a third $(208,000)$ of the estimated 690,000 HIV-related deaths globally in $2019,81 \%$ of these deaths occurring in the African region. ${ }^{3}$ A systematic review of postmortem studies from resource-limited settings found that almost half $(46 \%)$ of TB deaths were undiagnosed at the time of death. ${ }^{5}$ While over half $(62 \%)$ of new TB cases occur in the Southeast Asia and Western Pacific regions, almost three-quarters $(595,000)$ of all new HIV-associated TB cases occur in the African region; a quarter (24\%) of TB cases in the African region are estimated to be among people living with HIV, rising to around $60 \%$ in Lesotho, Eswatini, and South Africa. In 2019, only 56\% of the estimated 815000 incident HIV-positive TB cases were notified globally. ${ }^{3}$

\footnotetext{
' Centre for International Cooperation and Global TB Information, Research Institute of Tuberculosis, Japan Anti-Tuberculosis Association, Tokyo, Japan

${ }^{2}$ Institute for Global Health, University College London, London, UK

${ }^{3}$ Department of Global Coordination and Partnership on Antimicrobial Resistance, WHO, Geneva, Switzerland

${ }^{4}$ Department of Paediatrics, College of Medicine and Health Sciences, Hawassa University, Hawassa, Ethiopia

${ }^{5}$ Department of HIV, and Global Hepatitis and STIs WHO, Geneva, Switzerland

* Joint First Authors.

\section{Corresponding author:}

Yohhei Hamada, MD, MPH, Institute for Global Health, University College London, 30 Guilford Street, London WCIN IEH, UK.

Email: yohei.hamada0@gmail.com
} 
TB and HIV intersect where overcrowding and impoverishment meet, particularly affecting populations living in informal settlements, prisoners, people who inject drugs, migrants, and mine workers. Environmental factors such as poor living conditions characterized by overcrowding and poor ventilation and high prevalence of individual risk factors (e.g., smoking, undernutrition, and alcohol use) among these populations create the perfect environments for TB transmission. Poor access to health care exacerbates the epidemic further. For example, TB notification rates in South Africa's townships are among the highest in the world, exceeding 1000 per 100,000 persons. $^{6}$ The risk of TB disease in prisons is around 23 times higher than the general population. ${ }^{7}$ TB prevalence among HIV-positive inmates is as high as $30 \%$, while HIV prevalence among inmates with active TB can reach $40 \%-70 \%{ }^{8}$ These groups face additional challenges, making TB control even more difficult. Migrants and refugee populations experience language barriers, discrimination, unstable legal status and consequent fear of deportation, and mobility. ${ }^{9}$ Many mine workers face occupational risk factors, including poorly ventilated working environments and silica dust exposure. ${ }^{10}$ Given the variety of challenges they face, the need for a multisectoral response beyond health programs cannot be overemphasized.

The relationship between HIV and drug-resistant TB (DR-TB) is inconsistent. Epidemic levels of DR-TB have been reported in South Africa, the country with the greatest number of people living with HIV. ${ }^{11}$ Data from over 100,000 TB patients did not find a consistent association between multidrug-resistant TB (MDR-TB) and HIV, although poor data quality and limited coverage of HIV testing were limitations to this review ${ }^{12}$; nevertheless, in 11 of the countries included in the review, HIV-positive TB patients had a significantly higher odd of MDR-TB than HIV-negative individuals. Primary resistance acquired through transmission is estimated to account for a majority of DR-TB. ${ }^{13}$ However, the gap remains in the detection of DR-TB, with only $44 \%$ of the estimated incident rifampicinresistance/MDR-TB cases notified globally. ${ }^{3}$ The treatment success rate for MDR-TB remains suboptimal. In a large individual patient data meta-analysis, MDR-TB treatment success rate was $68 \%$ in HIV-negative patients, with a lower success rate of $55 \%$ in HIV-positive patients. ${ }^{14}$

\section{Pathogenesis and risk of TB in people living with HIV}

TB is the most common opportunistic infection in people living with HIV who have increased susceptibility to TB infection and are at high risk for progression to TB disease. $^{15}$ In most healthy individuals, TB infection is carried as latent $\mathrm{TB}$ infection (LTBI). Untreated HIV infection results in a progressive reduction in CD4 count, which increases the risk for progression from $\mathrm{TB}$ infection to active disease. There is an increased risk of TB soon after
HIV infection, even at high CD4 count ${ }^{16}$; this suggests that the increased risk is not solely because of CD4 cell depletion but also possibly because of functional impairment of TB-specific T cells. ${ }^{16,17}$ It is also suggested that HIV induces innate immune defects. HIV infection appears to limit macrophage ability to restrict the growth of TB bacilli. ${ }^{16}$ This underpins the importance of ART, regardless of CD4 count to prevent TB. ${ }^{18}$

ART induces immune reconstitution, thereby reducing the risk of TB disease by two-thirds. ${ }^{19} \mathrm{CD} 4$ count recovery and viral suppression are associated with a reduction in TB incidence while HIV viral load alone is not predictive of TB risk. $^{20}$ The risk of TB in people living with HIV remains higher than HIV-negative individuals even after initiation of ART. $^{21}$ A rapid expansion of TB-specific CD4 cells induces an exaggerated innate immune response, and in the presence of a high TB antigen load ART may induce TB-immune reconstitution inflammatory syndrome (IRIS). ${ }^{16}$

TB may in turn exacerbate HIV infection. Increased HIV viral load in lungs, blood, and cerebrospinal fluid is observed in people with TB. ${ }^{16}$ This is likely due to increased viral replication at the sites of granulomatous inflammation with abundant activated $\mathrm{T}$ cells and upregulation of HIV transcription by pro-inflammatory cytokines produced through the host immune response against TB. ${ }^{16}$ Epidemiological studies have shown an increased incidence of opportunistic infections in HIV-positive people with TB. ${ }^{16}$

\section{TB prevention}

Trials have shown that immediate ART initiation even at a high level of CD4 count significantly reduces the risk of TB. ${ }^{22,23}$ Thus, achieving the $95-95-95$ targets - $95 \%$ of people living with HIV knowing their HIV status, $95 \%$ of those diagnosed receiving ART, and $95 \%$ of them with viral suppression-is critical for TB prevention. Since 2016, the WHO has recommended ART for all, regardless of CD4 count. As of July 2019, 96\% of low- and middle-income countries (LMICs) have adopted the recommendation. ${ }^{24}$ However, only $67 \%$ of people living with HIV were on ART at the end of 2019. ${ }^{25}$ Moreover, ART alone is insufficient to prevent TB. ${ }^{26}$ TB preventive treatment (TPT) provides additive protection even at higher CD4 counts and reduces mortality. 22,27,28

The sensitivity of LTBI tests in people living with HIV is limited and even lower in those with lower CD4 count, whose TB risk is higher. ${ }^{29}$ Trials in high TB burden countries have shown benefits of TPT regardless of LTBI test results. ${ }^{27,28,30}$ Hence, LTBI testing is not required as recommended by WHO except in settings with low TB incidence. $^{31}$

Six months of daily isoniazid, known as isoniazid preventive therapy (IPT), has been the mainstay of treatment with protective efficacy ranging between 40 and $60 \%$ for people living with HIV. ${ }^{32,33}$ However, studies in high TB transmission settings showed waning protection. ${ }^{34,35}$ In studies conducted in South Africa and Botswana, IPT of 
36 months or longer was associated with lower TB incidence than 6 months of IPT. ${ }^{36,37}$ Therefore, WHO conditionally recommends at least 36 months of IPT in people living with HIV in high-transmission settings who have an unknown or a positive-LTBI test; however, its uptake is very limited. ${ }^{31}$ In low TB transmission settings, 6 months of IPT has shown a long-term protective effect. ${ }^{38}$ Furthermore, a recent trial in Côte d'Ivoire demonstrated a sustained reduction of mortality for 6 years by 6 months of IPT in adults living with HIV with high CD4 count. ${ }^{28}$ Observational studies in Myanmar and Indonesia reported similar results. ${ }^{39,40}$ Optimal duration of IPT in high TB incidence settings depends on local TB epidemiology and transmission as well as availability of health infrastructure and acceptance and adherence to treatment. ${ }^{31}$

Other effective regimens include daily 3-4 months rifampicin; daily 3 months isoniazid and rifampin; and 3 months weekly isoniazid and rifapentine (3HP). ${ }^{31} 3 \mathrm{HP}$ is associated with less hepatotoxicity and higher treatment completion rates than 6-9 months IPT. ${ }^{31}$ In a trial in African countries, a single course of $3 \mathrm{HP}$ was as effective as two courses of 3HP given annually. ${ }^{41}$ Additionally, one month of daily rifapentine and isoniazid was shown to be noninferior to 9 months IPT. ${ }^{30}$ Studies have suggested that rifapentine can be coadministered with efavirenz and dolutegravir without jeopardizing antiretroviral activity. ${ }^{42,43}$

Most high TB burden countries have adopted TPT in policy though it has not translated into its access at scale. ${ }^{44}$ In 2019, data on the coverage of TPT were available only in 21 out of the 38 high TB and TB/HIV burden countries; 13 of them had $<50 \%$ coverage. $^{3}$ This failure is due to health system and operational barriers, ${ }^{45}$ in particular fear of creating isoniazid resistance despite lack of evidence, ${ }^{46}$ problems with patient acceptability, and concerns about stock-outs and program sustainability. ${ }^{47}$ Furthermore, as of June 2020, rifapentine was registered only in 14 countries. $^{3}$

Prompt identification and treatment of TB is critical to prevent transmission. Systematic screening for TB should be implemented as a package with TPT. People living with HIV are susceptible to nosocomial TB transmission due to their immunosuppression and frequent exposure to healthcare settings. ${ }^{13}$ Nosocomial outbreaks of DR-TB have been reported. ${ }^{13}$ Infection prevention and control needs to be strengthened to prevent such tragic events. However, data to evaluate its implementation are lacking. ${ }^{48}$ Specific guidance is available elsewhere. ${ }^{48}$

\section{People presenting to care with advanced HIV disease}

Despite increased access to ART, the decline in HIV-related deaths has plateaued in recent years. ${ }^{49} \mathrm{Up}$ to half of people living with HIV present or re-present to care with advanced disease (i.e., CD4 counts $<200$ cells $/ \mathrm{mm}^{3}$ ). ${ }^{49}$ People with advanced HIV disease suffer from multiple opportunistic infections and a package of interventions including TB diagnostics and TPT should be given. ${ }^{49}$ Multiple studies have trialled empirical TB treatment even without TB suggestive signs and symptoms in people living with HIV with low CD4 count but did not show successful results (Table 1). ${ }^{50-52}$ Until the availability of new data, TB screening and investigation should guide the initiation of TB treatment. There is a need to analyze the continuum of care for TB and HIV and improve programmatic implementation as discussed laterto fill these gaps.

\section{Clinical features}

TB signs and symptoms in people living with HIV are variable and depend on the degree of immunosuppression. While pulmonary manifestations are common in less immunocompromised patients, the risk of extrapulmonary TB increases with advanced immunosuppression and presents with various signs and symptoms, commonly including lymphadenopathy and pleural effusion. In a systematic review, $78.9 \%$ of $\mathrm{HIV}$-associated $\mathrm{TB}$ had at least one of cough, fever, night sweats, and weight loss, and thus WHO recommends TB screening based on those symptoms. ${ }^{53}$ However, people living with HIV on ART are more likely to be asymptomatic, and only around $50 \%$ have one of the above four symptoms. ${ }^{54}$ Chest radiographic findings also depend on the degree of immunosuppression: severely immunosuppressed patients typically present a primary TB pattern (hilar adenopathy, pleural effusion, middle or lower lobe infiltrates). ${ }^{55}$ Radiographic findings in those with high CD4 count are similar to HIV-negative individuals, including cavitation. $^{55}$

Extrapulmonary TB can affect any organ in the body and commonly involves pleura, lymph node, central nervous system, abdominal organs, pericardium, and bone and often presents as disseminated TB. ${ }^{56}$ Diagnosis of extrapulmonary TB is challenging, with most being managed without bacteriological confirmation. The delay in diagnosis increases mortality. ${ }^{57}$ New diagnostics including Xpert Ultra and lateral flow urine lipoarabinomannan assay (LF-LAM) offers a great opportunity to expedite diagnosis.

\section{Diagnosis}

In people living with HIV, sputum bacillary load is usually low, compromising sensitivity of bacteriological tests. ${ }^{58,59}$ WHO recommends Xpert MTB/RIF as the initial diagnostic test, given its diagnostic accuracy, rapid turn-around time $(2 \mathrm{~h})$, and the ability to identify rifampicin resistance. The test has a much higher sensitivity of $80-90 \%$ than sputum smear microscopy. ${ }^{60}$ Despite reduced time to treatment and a higher proportion of bacteriological confirmation, evidence for direct clinical benefit had been inconclusive ${ }^{61-63}$; however, in a recent individual patient data meta-analysis of 
Table I. Trials of empirical TB treatment in people living with HIV.

\begin{tabular}{|c|c|c|c|c|c|}
\hline Study & Country & Participants & Intervention & Control & Key results \\
\hline $\begin{array}{l}\text { Blanc et al., } \\
2018^{80}\end{array}$ & $\begin{array}{l}\text { Côte d'Ivoire, } \\
\text { Uganda, } \\
\text { Cambodia, and } \\
\text { Vietnam }\end{array}$ & $\begin{array}{l}\text { ART-naive HIV-I } \\
\text { infected adults with } \\
\text { CD4<100 cells } / \mu\end{array}$ & $\begin{array}{l}\text { ART and empirical TB } \\
\text { treatment }(N=522)\end{array}$ & $\begin{array}{l}\text { Extensive screening: } \\
\text { Xpert MTB/RIF on } \\
\text { sputum, LF-LAM } \\
\text { and CXR at baseline } \\
\text { and at any time if } \\
\text { symptomatic } \\
(N=525)\end{array}$ & $\begin{array}{l}\text { Occurrence of death } \\
\text { or invasive } \\
\text { bacterial diseases } \\
\text { at week } 24: \mathrm{HR} \\
0.93(95 \% \mathrm{Cl} \\
0.6 \mathrm{I}-\mathrm{I} .42)\end{array}$ \\
\hline $\begin{array}{l}\text { Grant et al., } \\
2019^{81}\end{array}$ & South Africa & $\begin{array}{l}\text { HIV-positive adults } \\
\text { (aged } \geq 18 \text { years) with } \\
\text { CD4 }<=150 \text { cells/ } \\
\mathrm{mm}^{3} \text { who did not } \\
\text { require urgent } \\
\text { hospital referral }\end{array}$ & $\begin{array}{l}\text { Empirical TB treatment } \\
\text { for high-risk groups } \\
\text { (LF-LAM positive, } \\
\text { BMI<I8.5 kg/m } \mathrm{m}^{2} \text { or } \mathrm{Hb} \\
<100 \mathrm{~g} / \mathrm{L}) ; \mathrm{TB} \\
\text { investigation for } \\
\text { medium-risk groups } \\
\text { (any TB symptoms); } \\
\text { and immediate ART } \\
\text { for low-probability } \\
\text { groups } \\
(\mathrm{N}=1507)\end{array}$ & $\begin{array}{l}\text { Treatment in } \\
\text { accordance with } \\
\text { South African } \\
\text { guidelines. } \\
(N=15 \mid 5)\end{array}$ & $\begin{array}{l}\text { Mortality rate at } \\
6 \text { months: } 19.0 \\
\text { P-y vs } 21.6 \text { deaths } \\
\text { per } 100 \text { p-y; } \\
\text { adjusted HR } 0.87 \\
(95 \% \mathrm{Cl} 0.6 \mathrm{I}- \\
\text { I.24) }\end{array}$ \\
\hline $\begin{array}{l}\text { Hosseinipour } \\
\text { et al., } 2016^{82}\end{array}$ & $\begin{array}{l}\text { Malawi, South } \\
\text { Africa, Haiti, } \\
\text { Kenya, Zambia, } \\
\text { India, Brazil, } \\
\text { Zimbabwe, } \\
\text { Peru, and } \\
\text { Uganda }\end{array}$ & $\begin{array}{l}\text { Excluded patients with } \\
\text { confirmed or } \\
\text { suspected TB }\end{array}$ & $\begin{array}{l}\text { ART and empirical TB } \\
\text { treatment }(N=424)\end{array}$ & $\begin{array}{l}\text { ART and daily isoniazid } \\
\text { for } 24 \text { weeks } \\
(N=426)\end{array}$ & $\begin{array}{l}\text { Death or unknown } \\
\text { survival status at } \\
24 \text { weeks: } 22 / 424 \\
(5.2 \%) \text { vs } 22 / 426 \\
(5.2 \%) \\
\text { Risk difference: } \\
\quad-0.06 \% \text { ( } 95 \% \\
\text { Cl }-3.05 \text { to } 2.94)\end{array}$ \\
\hline
\end{tabular}

Note: TB: tuberculosis; ART: antiretroviral therapy; CXR: chest radiography; LF-LAM: lateral flow urine lipoarabinomannan assay; HR: hazard ratio; Cl: confidence interval; BMl: body mass index; Hb: hemoglobin.

RCTs, people living with HIV tested with Xpert MTB/RIF had $24 \%$ lower mortality than those tested with smear microscopy. ${ }^{64}$ A new version of this test, Xpert Ultra, has increased sensitivity by $12 \%$ in sputum samples among people living with HIV $^{65}$ Xpert Ultra incorporated a semiquantitative "trace" category to identify paucibacillary TB, which is more common in HIV-positive individuals. ${ }^{66}$ The WHO recommends that "trace results" should be interpreted as true positive in people living with $\mathrm{HIV}^{65}$

According to a UNAIDS survey in 2020, WHOrecommended rapid tests for TB were available in most facilities providing HIV testing and care in 12 out of 30 high TB/HIV burden countries. ${ }^{67}$ However, data on the number of HIV-associated TB diagnosed with these tests are lacking. Challenges in the scale of Xpert include lack of knowledge among clinical staff, insufficient support for maintenance, and a high price (at least US\$9.98 per cartridge) ${ }^{68}$

LF-LAM has emerged as an additional point-of-care test for TB in people living with HIV. ${ }^{69,70}$ LF-LAM is recommended to assist diagnosis of TB in people living with HIV who have signs and symptoms of TB or a low CD4 count $\left(<200\right.$ cells $/ \mathrm{mm}^{3}$ for inpatients and $<100$ for outpatients); and those who are seriously ill. ${ }^{71}$ The sensitivity of LF-LAM is highest when CD4 count is low, but it is still around $50 \%$ with $84 \%-98 \%$ specificity. ${ }^{65}$ The LF-LAM is affordable (US\$3.5 per unit) and can be used in peripheral facilities. As of 2019, only 13 of the high TB burden countries had adopted it, and the number of people accessing it is unknown. ${ }^{3}$ Treatment initiation guided by LFLAM showed a reduction of mortality in HIV-positive inpatients, ${ }^{70}$ and its use as a screening tool irrespective of symptoms may also reduce mortality. ${ }^{72}$ Hence, the adoption and rollout of LF-LAM should be accelerated. Recently, a novel LF-LAM (SILVAMP TB LAM, Fujifilm) has shown improved sensitivity. ${ }^{73}$

Diagnosing TB is even more complex in children due to difficulty in obtaining sputum and paucibacillary load. ${ }^{74}$ Both culture and molecular studies have a very low sensitivity on induced sputum or gastric lavage in children. ${ }^{74,75}$ Xpert testing using alternative samples have been explored. In a systematic review, sensitivity and specificity of Xpert using stool samples were $98 \%$ and $57 \%$ in children. ${ }^{76} \mathrm{WHO}$ new guidelines recommend Xpert testing in gastric aspirate, nasopharyngeal aspirate, and stool samples not only sputum in children. ${ }^{65}$ 
Table 2. Diagnostic accuracy of Xpert MTB/RIF in extrapulmonary specimens.

\begin{tabular}{lll}
\hline Type of specimens & Sensitivity, 95\% Cl & Specificity, 95\% Cl \\
\hline Cerebrospinal fluid & $71.1 \%(60.9-80.4)$ & $98.0 \%(97.0-98.8)$ \\
Pleural fluid & $50.9 \%(39.7-62.8)$ & $99.2 \%(98.2-99.7)$ \\
Pleural tissue & $30.5 \%(3.5-77.8)$ & $97.4 \%(92.1-99.3)$ \\
Lymph node aspirate & $87.6 \%(81.7-92.0)$ & $86.0 \%(78.4-91.5)$ \\
Lymph node tissue & $84.4 \%(74.7-91.0)$ & $78.9 \%(52.6-91.5)$ \\
Urine & $82.7 \%(69.6-91.1)$ & $98.7 \%(94.8-99.7)$ \\
Bone or joint fluid & $97.2 \%(89.5-99.6)$ & $90.2 \%(55.6-98.5)$ \\
Bone tissue & $91.8 \%(82.5-96.8)$ & $82.0 \%(56.6-94.9)$ \\
Peritoneal fluid & $59.2 \%(45.2-73.5)$ & $97.9 \%(96.2-99.1)$ \\
Pericardial fluid & $65.7 \%(46.3-81.4)$ & $96.0 \%(85.8-99.3)$ \\
Blood' $^{\prime}$ & $56 \%(21-86)$ and $94 \%(85-98)$ & $7 \%(0-34)$ and $98 \%(94-99)$ \\
Vitreous fluid $^{2}$ & $22.3 \%(14.0 \%-32.7)$ & $100 \%(95.5-100)$
\end{tabular}

Note: Cl: confidence interval. Data from a Cochrane review of Xpert MTB/RIF for extrapulmonary TB unless otherwise indicated. ${ }^{65}$

'Sensitivities and specificities were not pooled from two studies.

${ }^{2}$ Sharma et al., 2017.66

New WHO guidelines recommend the use of Xpert MTB/RIF in various samples including cerebrospinal fluid, lymph node aspirate, lymph node biopsy, pleural fluid, peritoneal fluid, pericardial fluid, synovial fluid, urine, and blood for the diagnosis of extrapulmonary TB although the sensitivity remains suboptimal (Table 2$).^{77,78}$ Adenosine deaminase, an enzyme involved in purine metabolism, in pleural and other fluids is a useful diagnostic marker for extrapulmonary TB. A systematic review showed its sensitivity and specificity of $93 \%$ and $90 \%$, respectively. ${ }^{79}$ However, its availability is limited in LMIC.

\section{Treatment}

\section{Drug-susceptible TB treatment}

The treatment regimen for drug-susceptible TB does not differ by HIV status. Treatment should be given daily rather than intermittently due to a higher risk of failure. ${ }^{80}$ ART substantially improves outcomes and should be given to all. Extension of treatment beyond 6 months is not required because of HIV infection. Six months of treatment is associated with a higher risk of failure than an extended treatment only in the absence of ART. ${ }^{80}$ Some experts recommend an extension in certain forms of extrapulmonary TB (e.g., central nervous system). High-dose rifampicin $(15 \mathrm{mg} / \mathrm{kg})$ given for the first 2 months has shown a reduction of mortality in people living with HIV with CD4 count $<100$ cells $/ \mathrm{mm}^{3}$ without increased risk of hepatotoxicity. ${ }^{81}$ A recent RCT demonstrated a noninferiority of a 4-month regimen (including high-dose rifapentine, isoniazid, moxifloxacin, and pyrazinamide) to the standard regimen, which included a subgroup of HIVpositive participants. ${ }^{82}$ In another RCT, in children (including HIV-positive children) with minimal TB, shortening the continuation phase into 2 months was noninferior. $^{83}$

The management of extrapulmonary TB is similar in HIV-positive and -negative individuals. Corticosteroids have been shown to reduce mortality from TB meningitis in HIV-negative individuals, but data are limited for people living with HIV. ${ }^{84}$ For pericarditis, a systematic review suggested that steroid may reduce deaths in HIV-negative patients, but no benefit was found among HIV-positive participants. ${ }^{85}$ Data are very limited in those on ART.

\section{Drug-resistant TB treatment}

Recommended treatment regimens for DR-TB are the same for HIV-positive and -negative individuals. ${ }^{86}$ Shorter treatment regimens now recommended by the WHO are promising to improve outcomes. ${ }^{86}$ In an RCT, mortality was higher among HIV-positive participants given 9-11 months regimens than long-term regimens; however, this was not statistically significant. ${ }^{87}$ In programmatic data from South Africa, a shorter all-oral bedaquiline-containing regimen resulted in higher success rate than a shorter regimen including an injectable agent ( $73 \%$ vs $60 \%)$, with a similar effect observed in HIV-positive participants. ${ }^{86}$ In the NixTB trial, 6 months of bedaquiline, pretomanid, and linezolid resulted in treatment success in 91\% of HIV-positive participants who had extensively drug-resistant $\mathrm{TB}$ or treatment-intolerant or nonresponsive MDR-TB. ${ }^{88}$ ART should be started as soon as possible irrespective of drug resistance status, although interactions and shared toxicity between ART and MDR-TB drugs may complicate management. For example, close monitoring of QT prolongation is needed when delamanid and/or bedaquiline is coadministered with protease inhibitors. 


\section{Timing of antiretroviral treatment}

WHO recommends ART should be started as soon as possible within two weeks of initiating TB treatment, regardless of CD4 count. In 2019, 88\% of notified HIVpositive TB patients worldwide received ART. ${ }^{3}$ Starting ART during TB therapy reduces the risk of death by around three-fifths. ${ }^{89}$ TB and HIV co-treatment is complicated by interactions between some anti-TB drugs, notably rifampicin, and several commonly used antiretroviral drugs. Detailed information is available elsewhere (https://www. hiv-druginteractions.org/).

\section{Treatment of IRIS}

IRIS can present as new TB diagnosis in a patient recently started on ART (unmasking TB), or as paradoxical IRIS, worsening of symptoms after initiation of TB treatment. The risk of IRIS increases with decreasing CD4 count at ART initiation. ${ }^{90}$ Studies have shown that mortality due to TBIRIS is low $(0.8 \%)$ except for TB meningitis ${ }^{91}$; however, morbidity remains significant. Nevertheless, ART should be started as soon as possible within the aforementioned time frame. Immediate initiation of ART in TB meningitis was not found to reduce mortality but was associated with severe adverse events. ${ }^{92}$ The optimal timing of ART in TB meningitis is uncertain, and it needs to be initiated with caution.

In an RCT in South Africa, prednisone given 4 weeks after initiation of ART reduced the risk of TB-related IRIS by $30 \%$ without increasing risk of cancer and severe infection. ${ }^{93}$ Steroids are also shown to reduce the morbidity of TB-IRIS and are commonly used to treat IRIS. ${ }^{94}$

\section{Pregnancy and HIV-associated TB}

TB is one of the common causes of morbidity and mortality in women of reproductive age. ${ }^{95,96} \mathrm{~TB}$ prevalence in pregnant and postpartum women in HIV-prevalent countries is more than three times higher than low HIV burden countries. ${ }^{97}$ Risk of adverse birth outcomes is increased for HIV-positive pregnant women with TB. Risk of mother-tochild transmission of HIV has been reported to increase 2.5 -fold, ${ }^{98}$ while perinatal mortality has been reported to increase sixfold. ${ }^{99}$ The coverage of ART among pregnant women was $85 \%$ globally in 2019 while a wide variation existed by region. $^{25}$

Symptom screening has a lower sensitivity in HIVpositive pregnant women than nonpregnant individuals. ${ }^{54}$ A recent trial showed increased case detection by universal sputum testing by Xpert in HIV-positive pregnant women. ${ }^{100}$ Strategies to expedite the diagnosis of TB among pregnant women are urgently needed.

WHO recommends TPT regardless of pregnancy status. ${ }^{36}$ A recent clinical trial reported more frequent adverse pregnancy outcomes among women with HIV given IPT during gestation, ${ }^{101}$ yet observational studies reported a protective effect. ${ }^{31}$ The conflicting results might be explained by bias in observational studies and differences in study populations since the RCT appeared to include women who were less at risk for TB than observational studies. It should also be noted that loss to HIV care after delivery tends to increase, ${ }^{102}$ which can result in a missed opportunity to receive TPT. Therefore, benefits and harms need to be weighed and discussed with pregnant women to decide timing to initiate TPT. Currently, data on the coverage of TPT among pregnant women are lacking.

\section{Program implementation}

In both HIV and TB programs, delays and difficulties in accessing services are important causes of patient loss to care and associated mortality. ${ }^{103-105}$ Decentralization of care, long practiced in TB control programs, is now accepted as a central way to delivering ART to increase coverage and retention in care. ${ }^{106}$

Integration of TB and ART services in settings with a high burden of both diseases is another key strategy for improving outcomes. ${ }^{107}$ In South Africa and Uganda, full integration of TB and HIV services reduced time to ART initiation and increased its uptake. ${ }^{108,109}$ Other documented benefits include reduced mortality, ${ }^{110}$ reduced delays in providing cotrimoxazole, ${ }^{111}$ reduced waiting times, ${ }^{112}$ and reduced loss to follow-up between antenatal, TB and HIV services. ${ }^{113}$ This latter example illustrates the importance of integrating TB and HIV services in other services where both diseases are commonly identified. ${ }^{110}$ While the risk of nosocomial transmission is often raised as a concern for the integration of TB and ART services, TB transmission occurs mostly from undiagnosed TB, and thus, effective management of both conditions can reduce the risk. ${ }^{114}$ In HIVprevalent settings, decentralizing MDR-TB treatment and care facilitates integrated management of both MDR-TB and HIV and has been found to increase initiation of MDRTB treatment and reduce time to treatment and is predicted to substantially reduce mortality. ${ }^{61,115}$

Engagement of community health workers can improve outcomes for both HIV and TB, ${ }^{116,117}$ and in settings with a high prevalence of coinfection, it makes sense to integrate TB and HIV services at the community level. ${ }^{118}$ Many countries in sub-Saharan Africa employ TB/HIV counselors to support joint activities. Recent reductions in donor support combined with a lack of national prioritization threaten the sustainability of TB/HIV lay counselors. ${ }^{119}$

Funding gaps remain large for both TB and HIV. In 2019,US\$18.6 billion was available for the HIV response, far below the target (US $\$ 26.2$ billion) set by UNAIDS for $2020 .^{25}$ US $\$ 13$ billion per year is required for TB program (and US\$2 billion for research), while only a half was available in 2019. ${ }^{3}$ These gaps would result in enormous health and social toll that could have been averted. 
Investment in the TB and HIV response would bring a significant economic return, US\$42 and US\$6.4 for every US dollar spent, respectively. ${ }^{120,}{ }^{121}$ Benefits from the investment extend to other diseases, as has been shown in the COVID-19 pandemic where platforms for TB and HIV program were leveraged to accelerate the response. Commitments made at the United Nations High-Level Meetings are being tested.

\section{Conclusions}

Notwithstanding progress in rollout of TB and HIV services, substantial gaps remain in the prevention, diagnosis, and treatment of HIV-associated TB. Innovations, such as shorter preventive and treatment regimens, Xpert Ultra, LFLAM, and new MDR-TB treatment regimens, offer an immense opportunity to bring HIV-associated TB under control. They must be rapidly adopted and scale up supported by adequate funding with robust monitoring of the uptake. Further research should aim to achieve durable TB protection, non-sputum-based point-of-care TB diagnosis, and more effective treatment of drug-susceptible and resistant TB across populations.

\section{Acknowledgements}

We gratefully acknowledge valuable inputs to our manuscript from Sabine Hermans Amsterdam Institute for Global Health and Development.

\section{Declaration of conflicting interests}

The author(s) declared no potential conflicts of interest with respect to the research, authorship, and/or publication of this article.

\section{Funding}

The author(s) received no financial support for the research, authorship, and/or publication of this article.

\section{ORCID iD}

Yohhei Hamada (D) https://orcid.org/0000-0002-9845-4267

\section{References}

1. De Cock KM and Chaisson RE. Will DOTS do it? A reappraisal of tuberculosis control in countries with high rates of HIV infection. Int J Tuberc Lung Dis 1999; 3(6): 457-465.

2. Nunn P, Williams B, Floyd K, et al. Tuberculosis control in the era of HIV. Nat Rev Immunol 2005; 5(10): 819-826.

3. WHO Global. Tuberculosis Report 2020. Geneva: World Health Organization, 2020. Available at: https://apps.who. int/iris/rest/bitstreams/1312164/retrieve accessed 27 November 2020.

4. Ford N, Shubber Z, Meintjes G, et al. Causes of hospital admission among people living with HIV worldwide: a systematic review and meta-analysis. The Lancet HIV 2015; 2(10): e438-e444.
5. Gupta RK, Lucas SB, Fielding KL, et al. Prevalence of tuberculosis in post-mortem studies of HIV-infected adults and children in resource-limited settings: a systematic review and meta-analysis. AIDS 2015; 29(15): 1987-2002.

6. Middelkoop K, Bekker L-G, Myer L, et al. Antiretroviral therapy and TB notification rates in a high HIV prevalence South African community. $J$ acquired immune deficiency syndromes 1999 2011; 56(3): 263-269.

7. Telisinghe L, Charalambous S, Topp SM, et al. HIV and tuberculosis in prisons in sub-Saharan Africa. The Lancet 2016; 388(10050): 1215-1227.

8. Dianatinasab M, Joulaei H, Ghorbani M, et al. Prevalence of tuberculosis in HIV-positive prisoners: a systematic review and meta-analysis. AIDS Rev 2018; 20(2): 114-124.

9. Abubakar I, Aldridge RW, Devakumar D, et al. The UCLlancet commission on migration and health: the health of a world on the move. The Lancet 2018; 392(10164): 2606-2654.

10. Stuckler D, Steele S, Lurie M, et al. Introduction: 'dying for gold': The effects of mineral miningon HIV, tuberculosis, silicosis, and occupational diseases in Southern Africa. Int $J$ Health Serv 2013; 43(4): 639-649.

11. Cox HS, McDermid C, Azevedo V, et al. Epidemic levels of drug resistant tuberculosis (MDR and XDR-TB) in a high HIV prevalence setting in Khayelitsha, South Africa. PLoS One 2010; 5(11): e13901.

12. Dean AS, Zignol M, Falzon D, et al. HIV and multidrugresistant tuberculosis: overlapping epidemics. Eur Respir $J$ 2014; 44(1): 251-254.

13. Khan PY, Yates TA, Osman M, et al. Transmission of drugresistant tuberculosis in HIV-endemic settings. Lancet Infect Dis 2019; 19(3): e77-e88.

14. Ahmad N, Ahuja SD, Akkerman OW, et al. Treatment correlates of successful outcomes in pulmonary multidrugresistant tuberculosis: an individual patient data metaanalysis. The Lancet 2018; 392(10150): 821-834.

15. Walker NF, Meintjes G, Wilkinson RJ. HIV-1 and the immune response to TB. Future Virol 2013; 8(1): 57-80.

16. Bell LCK, Noursadeghi M. Pathogenesis of HIV-1 and Mycobacterium tuberculosis co-infection. Nat Rev Microbiol 2018; 16(2): 80-90.

17. Canaday DH, Sridaran S, Van Epps P, et al. CD4+ T cell polyfunctional profile in HIV-TB coinfection are similar between individuals with latent and active TB infection. Tuberculosis (Edinb) 2015; 95(4): 470-475.

18. World Health Organization. Consolidated guidelines on the use of antiretroviral drugs for treating and preventing HIV infection. Recommendations for a public health approach. Second edition. Geneva, Switzerland: WHO, 2016.

19. Suthar AB, Lawn SD, del Amo J, et al. Antiretroviral therapy for prevention of tuberculosis in adults with HIV: a systematic review and meta-analysis. Plos Med 2012; 9(7): e1001270.

20. Martin-Echevarria E, Serrano-Villar S, Sainz T, et al. Development of tuberculosis in human immunodeficiency virus infected patients receiving antiretroviral therapy. Int J Tuberc Lung Dis 2014; 18(9): 1080-1084.

21. Gupta A, Wood R, Kaplan R, et al. Tuberculosis incidence rates during 8 years of follow-up of an antiretroviral 
treatment cohort in South Africa: comparison with rates in the community. PLoS One 2012; 7(3): e34156.

22. Group TAS, Danel C, Moh R, et al. A trial of early antiretrovirals and isoniazid preventive therapy in Africa. $N$ Engl $J$ Med 2015; 373(9): 808-822.

23. The INSIGHT START Study Group. Initiation of antiretroviral therapy in early asymptomatic HIV infection. New Engl J Med 2015; 373(9): 795-807.

24. World Health Organization. Treat all: policy adoption and implementation status in countries. Fact sheet, 2019. https:// apps.who.int/iris/bitstream/handle/10665/326035/WHOCDS-HIV-19.20-eng.pdf?ua=1 Accessed 29 November 2020.

25. UNAIDS. Fact sheet. Available at: http://www.unaids.org/ en/resources/factsheet. Accessed 29 November 2020.

26. Kufa T, Mabuto T, Muchiri E, et al. Incidence of HIVassociated tuberculosis among individuals taking combination antiretroviral therapy: a systematic review and meta-analysis. PLoS One. 2014; 9(11): e111209.

27. Rangaka MX, Wilkinson RJ, Boulle A, et al. Isoniazid plus antiretroviral therapy to prevent tuberculosis: a randomised double-blind, placebo-controlled trial. Lancet 2014; 384(9944): 682-690.

28. Badje A, Moh R, Gabillard D, et al. Effect of isoniazid preventive therapy on risk of death in west African, HIVinfected adults with high CD4 cell counts: long-term followup of the Temprano ANRS 12136 trial. Lancet Glob Health 2017; 5(11): e1080-e9.

29. Cattamanchi A, Smith R, Steingart KR, et al. Interferongamma release assays for the diagnosis of latent tuberculosis infection in HIV-infected individuals: A systematic review and meta-analysis. J Acquired Immune Deficiency Syndromes (1999) 2011; 56(3): 230-238.

30. Swindells S, Ramchandani R, Gupta A, et al. One month of Rifapentine plus isoniazid to prevent HIV-related tuberculosis. N Engl J Med 2019; 380(11): 1001-1011.

31. World Health Organization. WHO consolidated guidelines on tuberculosis: module 1: prevention: tuberculosis preventive treatment. Geneva, Switzerland: WHO, 2020.

32. Getahun H, Matteelli A, Chaisson RE, et al. Latent mycobacterium tuberculosis infection. $N$ Engl J Med 2015; 372(22): 2127-2135.

33. Akolo C, Adetifa I, Shepperd S, et al. Treatment of latent tuberculosis infection in HIV infected persons. Cochrane database Syst Rev 2010; 2010(1): Cd000171.

34. Churchyard GJ, Fielding KL, Grant AD. A trial of mass isoniazid preventive therapy for tuberculosis control. $N$ Engl $J$ Med 2014; 370(17): 1662-1663.

35. Hermans SM, Grant AD, Chihota V, et al. The timing of tuberculosis after isoniazid preventive therapy among gold miners in South Africa: a prospective cohort study. BMC Med 2016; 14: 45.

36. Samandari T, Agizew TB, Nyirenda S, et al. 6-month versus 36-month isoniazid preventive treatment for tuberculosis in adults with HIV infection in Botswana: a randomised, double-blind, placebo-controlled trial. Lancet 2011; 377(9777): 1588-1598.

37. Martinson NA, Barnes GL, Moulton LH, et al. New regimens to prevent tuberculosis in adults with HIV infection. N Engl J Med 2011; 365(1): 11-20.
38. Golub JE, Cohn S, Saraceni V, et al. Long-term protection from Isoniazid preventive therapy for tuberculosis in HIVinfected patients in a medium-burden tuberculosis setting: The TB/HIV in rio (THRio) study. Clin Infect Dis 2015; 60(4): 639-645.

39. Kyaw NTT, Kumar AMV, Kyaw KWY, et al. IPT in people living with HIV in Myanmar: a five-fold decrease in incidence of TB disease and all-cause mortality. Int $J$ Tuberc Lung Dis 2019; 23(3): 322-330.

40. Wisaksana R, Hartantri Y, Lestari M, et al. Benefit of isoniazide preventive therapy to reduce incident $\mathrm{TB}$, mortality and loss to follow-up in indonesian five-years cohort. In: 22nd International AIDS Conference; Amsterdam, The Netherlands, 2018.

41. Churchyard G, Cardenas V, Chihota V, et al., eds. Effectiveness of 3HP annually vs once for HIV-positive people: THE WHIP3TB TRIAL. In: Conference on Retrovirus and Opportunistic Infection; Boston, USA, 2020.

42. Podany AT, Bao Y, Swindells S, et al. Efavirenz Pharmacokinetics and pharmacodynamics in HIV-infected persons receiving rifapentine and isoniazid for tuberculosis prevention. Clin Infect Dis 2015; 61(8): 1322-1327.

43. Dooley KE, Savic R, Gupte A, et al. Once-weekly rifapentine and isoniazid for tuberculosis prevention in patients with HIV taking dolutegravir-based antiretroviral therapy: a phase 1/2 trial. Lancet HIV 2020; 7(6): e401-e409.

44. Jagger A, Reiter-Karam S, Hamada Y, et al. National policies on the management of latent tuberculosis infection: review of 98 countries. Bull World Health Organ. 2018;96(3): 173-84F.

45. Getahun H, Granich R, Sculier D, et al. Implementation of isoniazid preventive therapy for people living with HIV worldwide: barriers and solutions. AIDS 2010; 24 Suppl 5: S57-S65.

46. Balcells ME, Thomas SL, Godfrey-Faussett P, et al. Isoniazid preventive therapy and risk for resistant tuberculosis. Emerg Infect Dis 2006; 12(5): 744-751.

47. Teklay G, Teklu T, Legesse B, et al. Barriers in the implementation of isoniazid preventive therapy for people living with HIV in Northern Ethiopia: a mixed quantitative and qualitative study. BMC Public Health. 2016; 16(1): 840.

48. World Health Organization. WHO guidelines on tuberculosis infection prevention and control: 2019 update. Geneva, Switzerland: WHO, 2019.

49. World Health Organization. Guideline for managing advanced HIV disease and the timing for initiating antiretroviral therapy. Supplement to the 2016 consolidated guidelines on the use of antiretroviral drugs for treating and preventing HIV infection. Geneva, 2017.

50. Blanc FX, Badje AD, Bonnet M, et al. Systematic or testguided treatment for tuberculosis in HIV-infected adults. $N$ Engl J Med 2020; 382(25): 2397-2410.

51. Grant AD, Charalambous S, Tlali M, et al. Algorithm-guided empirical tuberculosis treatment for people with advanced HIV (TB Fast Track): an open-label, cluster-randomised trial. The Lancet HIV 2020; 7(1): e27-e37.

52. Hosseinipour MC, Bisson GP, Miyahara S, et al. Empirical tuberculosis therapy versus isoniazid in adult outpatients with advanced HIV initiating antiretroviral therapy 
(REMEMBER): a multicountry open-label randomised controlled trial. Lancet 2016; 387(10024): 1198-1209.

53. Getahun H, Kittikraisak W, Heilig CM, et al. Development of a standardized screening rule for tuberculosis in people living with HIV in resource-constrained settings: individual participant data meta-analysis of observational studies. PLOS Med 2011; 8(1): e1000391.

54. Hamada Y, Ford N, Schenkel K, et al. Three-month weekly rifapentine plus isoniazid for tuberculosis preventive treatment: a systematic review. Int J Tuberc Lung Dis 2018; 22(12): 1422-1428.

55. Barnes PF, Bloch AB, Davidson PT, et al. Tuberculosis in patients with human immunodeficiency virus infection. New Engl J Med 1991; 324(23): 1644-1650.

56. Naing C, Mak JW, Maung M, et al. Meta-analysis: the association between HIV infection and extrapulmonary tuberculosis. Lung 2013; 191(1): 27-34.

57. Barr DA, Lewis JM, Feasey N, et al. Mycobacterium tuberculosis bloodstream infection prevalence, diagnosis, and mortality risk in seriously ill adults with HIV: a systematic review and meta-analysis of individual patient data. Lancet Infect Dis 2020; 20(6): 742-752.

58. Luetkemeyer AF, Kendall MA, Wu X, et al. Evaluation of two line probe assays for rapid detection of Mycobacterium tuberculosis, tuberculosis (TB) drug resistance, and non-TB Mycobacteria in HIV-infected individuals with suspected TB. J Clin Microbiol 2014; 52(4): 1052-1059.

59. Johnson JL, Vjecha MJ, Okwera A, et al. Impact of human immunodeficiency virus type-1 infection on the initial bacteriologic and radiographic manifestations of pulmonary tuberculosis in uganda. Makerere University-Case Western Reserve University Research Collaboration. Int J Tuberc Lung Dis 1998; 2(5): 397-404.

60. Steingart KR, Schiller I, Horne DJ, et al. Xpert(R) MTB/RIF assay for pulmonary tuberculosis and rifampicin resistance in adults. Cochrane database Syst Rev 2014(1): CD009593.

61. Cox HS, Daniels JF, Muller O, et al. Impact of decentralized care and the Xpert MTB/RIF test on rifampicin-resistant tuberculosis treatment initiation in khayelitsha, South Africa. Open Forum Infect Dis 2015; 2(1): ofv014.

62. Theron G, Zijenah L, Chanda D, et al. Feasibility, accuracy, and clinical effect of point-of-care Xpert MTB/RIF testing for tuberculosis in primary-care settings in Africa: A multicentre, randomised, controlled trial. Lancet. 2014; 383(9915):424-435.

63. Hermans S, Caldwell J, Kaplan R, et al. The impact of the roll-out of rapid molecular diagnostic testing for tuberculosis on empirical treatment in Cape Town, South Africa. Bull World Health Organ. 2017;95(8):554-563.

64. Di Tanna GL, Khaki AR, Theron G, et al. Effect of Xpert MTB/RIF on clinical outcomes in routine care settings: individual patient data meta-analysis. Lancet Glob Health 2019; 7(2): e191-e199.

65. World Health Organization. WHO consolidated guidelines on tuberculosis: module 3: diagnosis - rapid diagnostics for tuberculosis detection. Geneva, Switzerland: WHO, 2020.

66. Esmail A, Tomasicchio M, Meldau R, et al. Comparison of Xpert MTB/RIF (G4) and Xpert ultra, including trace readouts, for the diagnosis of pulmonary tuberculosis in a TB and HIV endemic setting. Int J Infect Dis 2020; 95: 246-252.

67. UNAIDS National Commitments and Policy Instrument 2020. http://lawsandpolicies.unaids.org/ Accessed 29 November 2020.

68. England K, Masini T, Fajardo E. Detecting tuberculosis: rapid tools but slow progress. Public Health Action 2019; 9(3): 80-83.

69. Lawn SD, Kerkhoff AD, Burton R, et al. Diagnostic accuracy, incremental yield and prognostic value of determine TB-LAM for routine diagnostic testing for tuberculosis in HIV-infected patients requiring acute hospital admission in South Africa: a prospective cohort. BMC Med 2017; 15(1): 67.

70. Peter JG, Zijenah LS, Chanda D, et al. Effect on mortality of point-of-care, urine-based lipoarabinomannan testing to guide tuberculosis treatment initiation in HIV-positive hospital inpatients: a pragmatic, parallel-group, multicountry, open-label, randomised controlled trial. Lancet. 2016; 387(10024): 1187-1197.

71. WHO. Lateral flow urine lipoarabinomannan assay (LFLAM) for the diagnosis of active tuberculosis in people living with HIV. Policy Update 20192019.

72. Gupta-Wright A, Corbett EL, van Oosterhout JJ, et al. Rapid urine-based screening for tuberculosis in HIV-positive patients admitted to hospital in Africa (STAMP): a pragmatic, multicentre, parallel-group, double-blind, randomised controlled trial. The Lancet 2018; 392(10144): 292-301.

73. Broger T, Sossen B, du Toit E, et al. Novel lipoarabinomannan point-of-care tuberculosis test for people with HIV: a diagnostic accuracy study. Lancet Infect Dis 2019; 19(8): 852-861.

74. Kumar MK, Kumar P and Singh A. Recent advances in the diagnosis and treatment of childhood tuberculosis. J Nat Sci Biol Med 2015; 6(2): 314-320.

75. Bunyasi EW, Tameris M, Geldenhuys H, et al. Evaluation of Xpert(R) MTB/RIF assay in induced sputum and gastric lavage samples from young children with suspected tuberculosis from the MVA85A TB vaccine trial. PLoS One 2015; 10(11): e0141623.

76. Mesman AW, Rodriguez C, Ager E, et al. Diagnostic accuracy of molecular detection of mycobacterium tuberculosis in pediatric stool samples: a systematic review and metaanalysis. Tuberculosis (Edinb) 2019; 119: 101878.

77. Kohli M, Schiller I, Dendukuri N, et al. Xpert((R)) MTB/RIF assay for extrapulmonary tuberculosis and rifampicin resistance. Cochrane database Syst Rev 2018; 8: Cd012768.

78. Sharma K, Gupta V, Sharma A, et al. Gene Xpert MTB/RIF assay for the diagnosis of intra-ocular tuberculosis from vitreous fluid samples. Tuberculosis (Edinb) 2017; 102: 1-2.

79. Aggarwal AN, Agarwal R, Sehgal IS, et al. Adenosine deaminase for diagnosis of tuberculous pleural effusion: A systematic review and meta-analysis. PloS one 2019; 14(3): e0213728.

80. World Health Organization. Guidelines for treatment of drug-susceptible tuberculosis and patient care - 2017 update. Geneva, Switzerland: WHO, 2017.

81. Merle CS, Floyd S, Ndiaye A, et al. And on behalf of the Rafa Team. High-dose rifampicin tuberculosis treatment regimen 
to reduce 12-month mortality of $\mathrm{TB} / \mathrm{HIV}$ co-infected patients: the RAFA trial result. In: 21st International AIDS Conference, Durban, South Africa, 2016.

82. Dorman S. The design and primary efficacy results of study 31/A5349. Symposium SP-10, 51st union world lung health conference, 2020.

83. Wobudeya E, Chabala C, Hesseling A.C, et al. On behalf of the SHINE Trial Team. Shorter treatment for minimal tuberculosis in children: main findings from the SHINE trial. LB-2056-24. 51st union world lung health conference, 2020.

84. Prasad K, Singh MB and Ryan H. Corticosteroids for managing tuberculous meningitis. Cochrane database Syst Rev. 2016; 4: Cd002244.

85. Wiysonge CS, Ntsekhe M, Thabane L, et al. Interventions for treating tuberculous pericarditis. Cochrane database Syst Rev 2017; 9: Cd000526.

86. World Health Organization. WHO consolidated guidelines on tuberculosis. Module 4: treatment - drug-resistant tuberculosis treatment. Geneva, Switzerland: WHO, 2020.

87. Nunn AJ, Phillips PPJ, Meredith SK, et al. A trial of a shorter regimen for rifampin-resistant Tuberculosis. New Engl J Med 2019; 380(13): 1201-1213.

88. Everitt D, Conradie F, Crook A, et al. Efficacy and safety outcomes (HIV subgroup analysis) in the NIX-TB Trial bedaquiline, pretomanid and linezolid for treatment of extensively resistant,intolerant or non-responsive pulmonary multidrug-resistant tuberculosis. AIDS 2020; abstract number: OAB0502.

89. Odone A, Amadasi S, White RG, et al. The impact of antiretroviral therapy on mortality in HIV positive people during tuberculosis treatment: a systematic review and metaanalysis. PLoS One 2014; 9(11): e112017.

90. Namale PE, Abdullahi LH, Fine S, et al. Paradoxical TBIRIS in HIV-infected adults: a systematic review and metaanalysis. Future Microbiol 2015; 10(6): 1077-1099.

91. Abay SM, Deribe K, Reda AA, et al. The effect of early initiation of antiretroviral therapy in tb/hiv-coinfected patients: A systematic review and meta-analysis. J Int Assoc Providers AIDS Care 2015; 14(6): 560-570.

92. Török ME, Yen NT, Chau TT, et al. Timing of initiation of antiretroviral therapy in human immunodeficiency virus (HIV)-associated tuberculous meningitis. Clin Infect Dis 2011; 52(11): 1374-1383.

93. Meintjes G, Stek C, Blumenthal L, et al. Prednisone for the prevention of paradoxical tuberculosis-associated IRIS. New Engl J Med 2018; 379(20): 1915-1925.

94. Meintjes G, Wilkinson RJ, Morroni C, et al. Randomized placebo-controlled trial of prednisone for paradoxical tuberculosis-associated immune reconstitution inflammatory syndrome. AIDS. 2010; 24(15): 2381-2390.

95. Grange J, Adhikari M, Ahmed Y, et al. Tuberculosis in association with HIV/AIDS emerges as a major nonobstetric cause of maternal mortality in Sub-Saharan Africa. Int $J$ Gynaecol Obstet. 2010; 108(3): 181-183.

96. Sugarman J, Colvin C, Moran AC, et al. Tuberculosis in pregnancy: an estimate of the global burden of disease. Lancet Glob Health 2014; 2(12): e710-e716.
97. Mathad JS and Gupta A. Tuberculosis in pregnant and postpartum women: epidemiology, management, and research gaps. Clin Infect Dis 2012; 55(11): 1532-1549.

98. Gupta A, Bhosale R, Kinikar A, et al. Maternal tuberculosis: a risk factor for mother-to-child transmission of human immunodeficiency virus. J Infect Dis 2011; 203(3): 358-363.

99. Getahun H, Sculier D, Sismanidis C, et al. Prevention, diagnosis, and treatment of tuberculosis in children and mothers: evidence for action for maternal, neonatal, and child health services. J Infect Dis 2012; 205(Supp1 2): S216-S227.

100. Martinson N, Motihaoleng K, Variava E, et al. Universal sputum testing vs. symptom-based testing for tuberculosis (TB) in HIV-infected pregnant women: a clusterrandomized implementation trial in South Africa. In: 9th IAS Conference on HIV Science. Pari, France, 2017.

101. Gupta A, Montepiedra G, Aaron L, et al. Randomized trial of safety of isoniazid preventive therapy during or after pregnancy. Top Antivir Med. 2018; 26: 60s.

102. Adams JW, Brady KA, Michael YL, et al. Postpartum engagement in HIV care: an important predictor of long-term retention in care and viral suppression. Clin Infect Dis 2015; 61(12): 1880-1887.

103. Govindasamy D, Ford N and Kranzer K. Risk factors, barriers and facilitators for linkage to antiretroviral therapy care: a systematic review. AIDS 2012; 26(16): 2059-2067.

104. Brasil PE and Braga JU. Meta-analysis of factors related to health services that predict treatment default by tuberculosis patients. Cad Saude Publica 2008; 24(Suppl 4): s485-s502.

105. Castelnuovo B. A review of compliance to anti tuberculosis treatment and risk factors for defaulting treatment in Sub Saharan Africa. Afr Health Sci 2010; 10(4): 320-324.

106. Kredo T, Ford N, Adeniyi FB, et al. Decentralising HIV treatment in lower- and middle-income countries. Cochrane database Syst Rev 2013; 6: CD009987.

107. Legido-Quigley H, Montgomery CM, Khan P, et al. Integrating tuberculosis and HIV services in low- and middleincome countries: a systematic review. Trop Med Int Health 2013; 18(2): 199-211.

108. Kerschberger B, Hilderbrand K, Boulle AM, et al. The effect of complete integration of HIV and TB services on time to initiation of antiretroviral therapy: A before-after study. PLoS One 2012; 7(10): e46988.

109. Hermans SM, Castelnuovo B, Katabira C, et al. Integration of HIV and TB services results in improved TB treatment outcomes and earlier prioritized ART initiation in a large urban HIV clinic in Uganda. J Acquir Immune Defic Syndr 2012; 60(2): e29-e35.

110. Suthar AB, Rutherford GW, Horvath $\mathrm{T}$, et al. Improving antiretroviral therapy scale-up and effectiveness through service integration and decentralization. AIDS 2014; 28(Suppl 2): S175-S185.

111. Owiti P, Zachariah R, Bissell K, et al. Integrating tuberculosis and HIV services in rural Kenya: uptake and outcomes. Public Health Action 2015; 5(1): 36-44.

112. Ndagijimana A, Rugigana E, Uwizeye CB, et al. One-stop TB-HIV services evaluation in Rwanda: comparison of the 2001-2005 and 2006-2010 cohorts. Public Health Action 2015; 5(4): 209-213. 
113. Pfeiffer J, Montoya P, Baptista AJ, et al. Integration of HIV/ AIDS services into African primary health care: lessons learned for health system strengthening in Mozambique a case study. $J$ Int AIDS Soc 2010; 13: 3.

114. Loveday M and Zweigenthal V. TB and HIV integration: obstacles and possible solutions to implementation in South Africa. Trop Med Int Health 2011; 16(4): 431-438.

115. Gilbert JA, Long EF, Brooks RP, et al. Integrating community-based interventions to reverse the convergent TB/HIV epidemics in rural South Africa. PLoS One 2015; 10(5): e0126267.

116. Lewin S, Munabi-Babigumira S, Glenton C, et al. Lay health workers in primary and community health care for maternal and child health and the management of infectious diseases. Cochrane database Syst Rev 2010; 2010(3): CD004015.
117. Mwai GW, Mburu G, Torpey K, et al. Role and outcomes of community health workers in HIV care in sub-Saharan Africa: a systematic review. J Int AIDS Soc 2013; 16: 18586.

118. Frasca $\mathrm{K}$ and Cohn J. Integration of HIV and tuberculosis in the community. J Int Assoc Providers AIDS Care. 2014; 13(6): $534-538$

119. MSF. HIV/TB counselling: Who Is Doing the Job. Johannesburg: Médecins Sans Frontières, 2015. Available at: http://www.msfaccess.org/sites/default/files/MSF_assets/ HIV_AIDS/Docs/AIDS_Report_IAS_\%20Counselling ENG_2015.pdf.

120. Lamontagne E, Over M, Stover J. The economic returns of ending the AIDS epidemic as a public health threat. Health Policy 2019; 123(1): 104-108.

121. Stop TB Partnership. The paradigm shift 2018-2022. http:// www.stoptb.org/assets/documents/global/plan/GPR_20182022_Digital.pdf Accessed 29 November 2020. 